\title{
Family Quality of Life: A Qualitative Inquiry
}

\author{
Denise Poston, Ann Turnbull, Jiyeon Park, Hasheem Mannan, Janet Marquis, and Mian Wang
}

\begin{abstract}
In this qualitative inquiry we investigated the conceptualization of family quality of life. Focus groups and individual interviews were conducted with 187 individuals: family members (e.g., parents, siblings) of children with a disability, individuals with a disability, family of children without a disability, service providers, and administrators. Data were collected in urban and rural settings to elicit the participants' understanding of family quality of life. Ten domains of family quality of life were identified and described in terms of subdomains, indicators, and key points raised by participants. Implications are discussed in terms of future directions for research and family support.
\end{abstract}

Researchers from the international disability community have made significant progress in conceptualizing and measuring the quality of life of individuals with developmental disabilities (Cummins, 1997; Felce, 1997; Goode, 1997; Hughes \& Hwang, 1996; Schalock, 1996, 1997, 2000). A core international team of researchers synthesized the alternative conceptualizations of quality of life outcomes into a consensus document focusing on conceptualization, measurement, and application (Schalock et al., 2002). The consensus document incorporates the following eight domains of quality of life for individuals with disabilities: Emotional Well-Being, Interpersonal Relations, Material WellBeing, Personal Development, Physical Well-Being, Self-Determination, Social Inclusion, and Rights.

Although individual quality of life research has produced sufficient momentum to result in an international consensus document, family quality of life is at the very beginning of the conceptualization process. Family quality of life as a policy/program outcome is a natural extension from the work on individual quality of life, especially given the strong emphasis in the disability field on a family-centered service delivery model. Since the mid-to-late 1980 s, there has been a growing recognition of the importance of family-centered service delivery characterized by family choice, a family strengths perspective, and the family as the unit of support (Allen \& Petr, 1996; Bailey \& McWilliam, 1993; Dunst, Johnson, Trivette, \& Hamby, 1991; Turnbull, Turbiville, \&
Turnbull, 2000). Bailey and colleagues (1998) have proposed quality of life of families who have a child with disabilities as a "useful indicator of outcomes of policy initiatives" (p. 322).

Conceptualization of family quality of life outcomes has been extremely limited to date. In addition to focusing on the personal outcomes of individuals with disabilities, Gardner and associates (Accreditation Council, 1995) have also provided one of the few conceptualizations that includes family-oriented outcomes for the early intervention lifespan stage only. Currently, research on family quality of life is also being conducted in a three-country study involving Australia (Brown, Davey, Shearer, \& Kyrkou, in press), Canada (Brown, Isaacs, McCormack, Baum, \& Renwick, in press), and Israel (Neikrug, Judes, Roth, \& Krauss, in press).

Our purpose in the present study is to provide the conceptual foundation for a domain structure for family quality of life based on the perspectives of family members of children and youth with and without disabilities, service providers, and administrators. The research questions for this study were as follows: (a) What are the major domains of family quality of life? (b) What are the subdomains within each domain of family quality of life? (c) What are the indicators within domains? (d) How do the family quality of life perspectives of families with children who have disabilities contrast with the perspectives of parents of children without disabilities? We defined key 
terms in our research questions as follows: domains--core areas encapsulated within family quality of life; subdomains--the thematic categories within each domain; and indicators-statements that explicate the subdomains.

\section{Method}

From the beginning of the study, we established a participatory action research process that involved collaboration with family members, service providers, administrators, and researchers from education, human and social services, and health to ensure maximum rigor and relevance (Santelli, Singer, DiVenere, Ginsberg, \& Powers, 1998; Turnbull, Friesen, \& Ramirez, 1998). We used focus groups and individual interviews for data collection. Focus groups provided a responsive context for people who have not traditionally been encouraged to voice their perspectives on sensitive topics (Krueger, 1994; Rubin \& Rubin, 1995). Individual interviews were primarily used to gain the perspectives of parents who do not speak English at all or who speak English on a limited basis. Individual interviews enabled the use of interpreters, which would have been difficult to incorporate into focus groups. We also used individual interviews for three siblings of individuals with disabilities.

\section{Participants}

Focus groups. We conducted focus groups in three locations: (a) Kansas City, Kansas (urban), (b) New Orleans, Louisiana (urban), and (c) Granville County, North Carolina (rural). We collaborated with local participatory action research advisors (parent and professional leaders) in each setting and followed their advice about the most appropriate way to configure groups to maximize the participants' comfort and potential for responsiveness. In general, each location had (a) two focus groups of families with children who had disabilities, (b) two focus groups of families of children without disabilities, (c) one focus group of service providers, and (d) one focus group of administrators.

Tables 1 and 2 contain the demographic characteristics of family members and professionals, respectively. In collaboration with the local participatory action research advisors in each site, we used purposive, maximum variation, intensity, and convenience sampling strategies to recruit participants (Erlandson, Harris, Skipper, \& Allen, 1993; Krueger, 1994; Lincoln \& Guba, 1985; Patton, 1990).

Individual interviews. We conducted interviews with 18 parents for whom English was not their primary language. All of these interviews were conducted in the Kansas City area. We worked with parent leaders and agencies that provide direct services to children and families with limited English proficiency (e.g., school-based coordinators of the English as a Second Language program) to identify participants. The local leaders provided the first contact with families and assisted us in arranging for interpreters. Table 1 includes a demographic summary for the individual interviews. In addition, we interviewed 10 service providers who regularly provide supports and services to families with limited English proficiency. These service providers are included in the demographics in Table 2.

We also interviewed three siblings of individuals with disabilities in Kansas City. We interviewed them rather than conducting a focus group because the participatory action research advisor suggested that she thought interviews would be more comfortable for them.

\section{Data Collection}

Focus groups. We used a semi-structured interview guide to provide general direction for the focus group discussion, which included the following overarching questions with families: (a) When you hear the words family quality of life, what first comes to your mind? (b) Tell us about times when things have gone really well in your family. What helps things go well? (c) Tell us about times that have been especially tough in your family. What are the things that usually create tough times? (d) We constructed an interview guide of probes related to these questions. We asked service providers and administrators about quality of life within their own families as well as questions about their perspectives on the factors that contribute to a good quality of life for the families to whom they provide services.

Primary and assistant moderators met after each focus group to debrief on the quality of the moderation, the appropriateness of the questions and probes, and any participant issues that warranted reflection. The team also addressed emerging themes and confirmation of previous themes, with an emphasis on revising the probes to ensure the richest data possible in the broad data pool.

Most focus groups were comprised of 6 to 12 participants. We conducted these groups in two 
rounds, with the second round being held 3 to 4 months after the first. The purpose of having the second round was to explore issues in more depth and to include questions and issues that were not adequately addressed in the first round. Because of logistical difficulties, some participants were unable to come to the second round; therefore, to ensure an adequate group size, we included some new participants in the second round.

Each focus group lasted approximately 1.5 hours. At the conclusion of the focus groups, the moderator conducted an early member check by summarizing major points and soliciting feedback. We transcribed all focus group discussion and conducted a double-check of the tape and transcript to ensure accuracy.

Individual interviews. Nine graduate students conducted the individual interviews with families for whom English was not their primary language. We used similar procedures in the individual interviews as already described for focus groups regarding general sequence of questions, tape recording, and transcription.

\section{Data Analysis}

We used the constant comparative method of analyzing focus group and interview data to (a) generate categories, subcategories, and codes; (b) interpret patterns and themes; and (c) ensure rigor (Glaser \& Strauss, 1967; Lincoln, 1995; Lincoln \& Guba, 1985).

Generating Categories, Subcategories, and Codes

Initially, 6 members of our research team read two focus group transcripts (representing different types of groups and research sites) to identify text segments that appeared pertinent to the research questions. We met in pairs and discussed initial perspectives on emerging categories. We repeated this process with four more sets of transcripts for each of the three pairteams and pooled our perspectives on categories until we could formalize them into an initial codebook. We continued to read transcripts until all transcripts had been analyzed according to categories and the codebook had been revised seven more times. All 6 researchers agreed that the 90 codes in Version 11 of the codebook had a clear operational definition and represented a comprehensive categorization system. Disagreements among the members of the team were resolved through discussion and consensus building; the goal was to develop a credible and inclusive taxonomy representing a synthesis of the ideas of all members of the research team (Lincoln, 1995).

\section{Interpreting Patterns and Themes}

A total of 35 transcripts from the focus groups and 30 transcripts from the interviews resulted in approximately 1,900 single-spaced pages of transcripts. We placed all transcripts into Ethnograph (5.0), a software program that sorts data by categories. Based on the 11th version of the codebook, we used Ethnograph to sort all coded segments and provide printouts of all segments for each code. Through this process of constantly and continuously comparing codes, the research team sorted the data into 10 domains and 139 indicators of family quality of life. This sort formed the basis for the 12th version of the codebook.

Four members of the research team used the 12th and final version of the codebook to recode all 65 focus group and individual interview transcripts. A fifth member of the research team checked $30 \%$ of the transcripts to ensure coding completeness and accuracy.

Although this data-analysis procedure is described in somewhat of a linear manner the process of developing and refining codes and then coding and recoding transcripts occurred in a nonlinear fashion (Erlandson et al., 1993). The entire process took 16 months.

\section{Ensuring Rigor}

We ensured rigor through the incorporation of procedures to address credibility, transferability, and dependability (Lincoln, 1995; Lincoln \& Guba, 1985). We used three techniques for addressing credibility (accuracy of information): (a) triangulation of data, (b) peer debriefing, and (c) member checking (Erlandson et al., 1993; Lincoln \& Guba, 1985).

We triangulated data (i.e., the synthesis of multiple sources with the same information) by (a) gathering information from multiple sources (e.g., families of children and youth with and without disabilities, service providers, and administrators) and (b) multiple locations (e.g., Kansas City, New Orleans, and Granville County) and (c) using multiple researchers to collect and analyze data. We incorporated peer debriefing (i.e., inviting peers who were not immersed in the research to reflect and provide feedback on the methods and findings) by involving participatory action research committee 
Table 1 Participant Demographics: Family Members $(n=137)$

\begin{tabular}{|c|c|c|c|c|}
\hline Variable & $\begin{array}{l}\text { Families of } \\
\text { children with } \\
\text { disabilities } \\
(n=78)\end{array}$ & $\begin{array}{c}\text { Families who } \\
\text { use English } \\
\text { as a second } \\
\text { language } \\
(n=18)\end{array}$ & $\begin{array}{l}\text { Families of } \\
\text { children } \\
\text { without } \\
\text { disabilities } \\
(n=33)\end{array}$ & $\begin{array}{c}\text { Individuals } \\
\text { with } \\
\text { disabilities } \\
(n=8)\end{array}$ \\
\hline \multicolumn{5}{|l|}{ Gender } \\
\hline Female & 55 & 17 & 29 & 3 \\
\hline Male & 23 & 1 & 4 & 5 \\
\hline Missing information & 2 & 0 & 0 & 0 \\
\hline \multicolumn{5}{|l|}{ Ethnicity } \\
\hline African American & 42 & 0 & 16 & 6 \\
\hline Hispanic & 3 & 17 & 2 & 0 \\
\hline Caucasian & 26 & 0 & 13 & 2 \\
\hline Other & 4 & 1 & 2 & 0 \\
\hline Missing information & 3 & 0 & 0 & 0 \\
\hline \multicolumn{5}{|l|}{ Age } \\
\hline $10-19$ & 2 & $\mathrm{INA}^{\mathrm{a}}$ & 0 & 8 \\
\hline $20-29$ & 9 & & 5 & 0 \\
\hline $30-39$ & 24 & & 12 & 0 \\
\hline $40-49$ & 25 & & 12 & 0 \\
\hline $50-59$ & 10 & & 4 & 0 \\
\hline $60+$ & 2 & & 0 & 0 \\
\hline Missing information & 6 & & 0 & 0 \\
\hline \multicolumn{5}{|l|}{ Marital status } \\
\hline Married & 47 & INA & 20 & 0 \\
\hline Not married & 25 & & 13 & 8 \\
\hline Missing information & 6 & & 0 & 0 \\
\hline \multicolumn{5}{|l|}{ Employment status } \\
\hline Employed full-time & 39 & INA & 11 & 0 \\
\hline Employed part-time & 10 & & 5 & 0 \\
\hline Not employed & 21 & & 6 & 0 \\
\hline Full-time student & 2 & & 0 & 0 \\
\hline Missing information & 6 & & 1 & 8 \\
\hline \multicolumn{5}{|l|}{ Highest level of education completed } \\
\hline No high school diploma & 6 & INA & 2 & 8 \\
\hline High school graduate or GED & 15 & & 8 & 0 \\
\hline Some college, or college degree & 51 & & 22 & 0 \\
\hline Missing information & 6 & & 1 & 0 \\
\hline \multicolumn{5}{|l|}{ Relationship with the child } \\
\hline Biological parent & 51 & 18 & 32 & INA \\
\hline Foster parent & 3 & 0 & 0 & \\
\hline Adoptive parent & 5 & 0 & 0 & \\
\hline Other family member & 6 & 0 & 0 & \\
\hline Missing information & 13 & 0 & 1 & \\
\hline
\end{tabular}


Table 1 Continued

\begin{tabular}{|c|c|c|c|c|}
\hline Variable & $\begin{array}{l}\text { Families of } \\
\text { children } \\
\text { with } \\
\text { disabilities } \\
(n=78) \\
\end{array}$ & $\begin{array}{l}\text { Families who } \\
\text { use English as } \\
\text { a second } \\
\text { language } \\
(n=18)\end{array}$ & $\begin{array}{l}\text { Families of } \\
\text { children } \\
\text { without } \\
\text { disabilities } \\
(n=33) \\
\end{array}$ & $\begin{array}{c}\text { Individuals } \\
\text { with } \\
\text { disabilities } \\
(n=8)\end{array}$ \\
\hline \multicolumn{5}{|l|}{ Income } \\
\hline Low (annual income $<\$ 25,000$ ) & 17 & INA & 12 & 8 \\
\hline Moderate & 24 & & 14 & 0 \\
\hline High $(>\$ 50,000)$ & 18 & & 6 & 0 \\
\hline Missing information & 19 & & 1 & 0 \\
\hline \multicolumn{5}{|l|}{ Community size } \\
\hline Metro/urban & 49 & INA & 22 & 0 \\
\hline Small city/town & 6 & & 8 & 8 \\
\hline Rural area & 7 & & 2 & 0 \\
\hline Missing information & 8 & & 1 & 0 \\
\hline \multicolumn{5}{|c|}{ Age range of the child with a disability } \\
\hline Birth to 5 & 17 & INA & INA & 0 \\
\hline $5-13$ & 20 & & & 0 \\
\hline $13-21$ & 21 & & & 8 \\
\hline Over 21 & 3 & & & 0 \\
\hline Missing information & 17 & & & 0 \\
\hline \multicolumn{5}{|c|}{$\begin{array}{l}\text { Disability severity of the child with a } \\
\text { disability }\end{array}$} \\
\hline Mild & 6 & INA & INA & 4 \\
\hline Moderate & 33 & & & 4 \\
\hline Severe/very severe & 26 & & & 0 \\
\hline Missing information & 13 & & & 0 \\
\hline
\end{tabular}

${ }^{\mathrm{a}}$ Information not available.

members, other research colleagues at the same setting as the researchers, and family leaders. Finally, we used member checking (a) at the end of each focus group (as previously described), (b) at the beginning of the second round of focus groups (sharing a synthesis from the first round), and (c) by a formal member check conducted at the end of data analysis.

The formal member check included sending an executive summary of the results and a response form to 65 focus group participants. We received a $38 \%$ response rate. All responses confirmed the credibility of the summary; 3 participants provided comments for improving the focus group process (e.g., too much time lapsing between the first and second rounds of the focus groups; focus group location was too crowded).

Although transferability is not a crucial issue for qualitative studies (Maxwell, 1996), we intentionally sought to enhance transferability by including (a) different geographic locations to expand the diversity of the sample and (b) diverse participants with a wide variety of characteristics (e.g., families of children and youth with and without disabilities representing different ages and types of disabilities).

Dependability addresses the extent to which the research process is consistent across researchers. The research team included 16 people (5 of whom assumed primary responsibility) over 2 years. Using multiple researchers helped ensure that data were not weighted to reflect any one researcher's perspective (Brotherson \& Goldstein, 1992). The research team extensively discussed their agreements and disagreements in working to achieve consensus on categories, subcategories, codes, domains, and indicators. As a research team, we accounted for all changes in the 
Table 2 Participant Demographics: Professionals $(n=50)$

\begin{tabular}{lr}
\hline Variable & $n$ \\
\hline Gender & \\
Female & 46 \\
Male & 4 \\
Ethnicity & \\
$\quad$ African American & 5 \\
Hispanic & 2 \\
Caucasian & 43 \\
Other & 0 \\
Role & \\
Administrators & 17 \\
Service providers & 33 \\
Working field & \\
$\quad$ Education & 19 \\
Human/social services & 21 \\
Heath care & 8 \\
Combination & 2 \\
\hline
\end{tabular}

research process and all decisions related to coding by developing an audit trail involving five types of information: (a) raw data (e.g., interview guides, audiotapes), (b) data-reduction and analysis products (e.g., Ethnograph printouts, peer-debriefing notes), (c) data reconstruction and synthesis products (e.g., codebooks, final report), (d) process notes (e.g., decision diary, methodological notes), and (e) products describing intentions and dispositions (e.g., proposal, personal notes).

\section{Limitations of the Study}

Our research questions were focused on a beginning conceptualization of family quality of life. We believe it was entirely appropriate to use qualitative inquiry given the exploratory nature of research on family quality of life. Given the nature of qualitative inquiry, we caution against broad generalizations of these findings to all families -- those with and those without children with disabilities.

Four limitations of the study are (a) the lapsed time between the first and second round of interviews, (b) the difficulty in establishing rapport with the families with limited English proficiency, (c) a failure to provide re-translations of interview transcripts to assure reliability, and (d) a failure to conduct a confirmatory analysis of our data-analysis procedures.

In terms of the lapsed time between the first and second round interviews, typically this interval was 3 to 4 months. Because of this time lapse, some participants did not clearly remember what we had discussed in the first interview, which resulted in some redundancy. Furthermore, the rapport we had established dissipated somewhat over this period of time.

Although we had good intentions of interviewing families who have limited English proficiency, our intentions and the reality did not match. Many of the 18 families were extremely suspicious of researchers asking them personal questions about their families. Consequently, their responses were somewhat limited in content.

Our individual interviews with 18 family members with limited English proficiency included an interpreter, who provided an immediate interpretation of our questions to the parent and the parent's responses to us. We did not, however, have a second person re-translate the translation of the interview on the transcripts to assure reliability.

A final methodological limitation is that we did not have a professional peer conduct a confirmatory analysis of our analytic procedures; however, we used many other techniques to ensure credibility, as previously described.

\section{Findings}

In this section we report our findings related to (a) the definition of family; (b) family quality of life domains; (c) family quality of life domain definitions, subdomains, and indicators; and (d) contrast in perspectives of parents of children with and without disabilities. We believe we can best elucidate our findings by tying them to a family vignette-the Bell family described below. Caroline Bell was a participant in one of the focus groups.

Caroline Bell was a 63-year-old retired widow with two daughters, Bonita (age 30) and Myra (age 36). Caroline was the primary careprovider for her three grandchildren (Myra's children): Mike, Todd, and Louis, ages 12, 15, and 17, respectively. All had been diagnosed with autism. For the preceding 5 years, the children had, been in Caroline's custody because Myra had a "nervous breakdown" and was addicted to drugs. Bonita helped her mother look after the boys, but she had recently been diagnosed with lupus and experienced extreme fatigue. The two oldest children, Todd and Louis, were nonverbal and had extremely aggressive behavior. Recently, Louis punched Caroline in the eye and kicked her in the stomach. Todd was nonambulatory and needed help in all activities of daily living. Because of the constant demand of caring for Todd and Louis, Caroline believed that Mike was often neglected. 
Caroline had been told by social services that the boys needed to be in school, the house should be cleaner, and the holes in the walls that the boys made needed to be repaired. She feared that her grandsons would be taken and placed into foster care. Caroline loved her grandsons and desperately wanted to provide for their needs. "We've had fun with the boys. They are my life -- they're in my heart -- I love them very much."

Caroline wanted her grandsons to have an education but was having a hard time with the school system. The neighborhood school was inaccessible, so she had to demand that a ramp be built for Todd. An IEP meeting recently scheduled for Mike was subsequently canceled. Caroline was very worried that Mike's education was not in any way meeting his needs.

\section{Definition of Family}

We were keenly interested in the diverse ways in which the family participants described their family composition. After extensive discussion among our research team, we concluded that an appropriate definition of family is as follows: A family includes the people who think of themselves as part of the family, whether related by blood or marriage or not, and who support and care for each other on a regular basis.

According to our definition, the Bell family had 6 members. The U.S. Census would not consider them a family based on its definition of a family as a group of two or more people related by birth, marriage, or adoption who reside together (Iceland, 2000). Thus, the U.S. Census would not consider Myra and Bonita to be part of the same family with Caroline and the boys because Myra and Bonita did not live in the same residence. It is critically important in family research to ensure a closer match between the researcher's definition of family and the family's own definition, and we believe our definition is grounded in how families themselves characterized their membership. We visually illustrate our points in Figure 1. In Figure 1, Number 1, we show the 6 members of the Bell family.

\section{Contrast Between Individual and Family Quality of Life}

Throughout our data analysis, we wrestled with the similarities and differences between individual quality of life and family quality of life. To determine individual quality of life, we might ask each family member: "For me to have a good life, how important is it for me to get medical care when I need it?" In moving from an individual to a family unit of analysis for quality of life, we could ask each family member: "For my family to have a good life together, how important is it for my family members to get medical care when they need it?" As illustrated by these examples, family quality of life, as contrasted to individual quality of life, considers all family members in terms of what it takes for them to have a good life and their "aggregated" perspective.

All members of the Bell family had their own individual quality of life. Thus, an analysis could focus on asking each one of them questions separately to ascertain her or his perception of individual quality of life. Figure 1, Number 2 shows eight domains of individual quality of life within each of the family members. In the illustration, each circle has a different configuration of domains, showing that each of the Bell family members have different priorities, strengths, and needs related to each of the eight domains (we chose eight domains consistent with the individual quality of life domains conceptualized by the International Panel of Experts (Schalock et al., 2002) Special Interest Research Group on Quality of Life, 2000). The circles are not touching each other, indicating that the emphasis in individual quality of life is on the individual only and not on the individual's reciprocal interaction with others in his or her family context.

\section{Family Quality of Life Domains}

As contrasted to individual quality of life, family quality of life addresses the impact of individual quality of life on the family -- the interaction and reverberation of individual members as they produce the aggregate of family quality of life. Figure 2 depicts the domain structure that evolved from our data analysis. The data suggest a domain structure with two parts: (a) domains with an individual orientation and (b) domains with a family orientation. Domains with an individual orientation represent the idiosyncratic ways that the quality of life of individual family members has an impact on the quality of life of other family members and on the family as a whole. The six individual domains are Advocacy, Emotional Well-Being, Health, Physical Environment, Productivity, and Social Well-Being. We illustrate the impact that individual family members have on each other within the six domains in Figure 1, Number 3. Each individual family member has his or her own configuration of quality of life across the individually oriented domains. 
1. Family definition-We define the family membership according to the people who think of themselves as part of the Bell family, whether related by blood or marriage or not, and who support and care for each other on a regular basis.

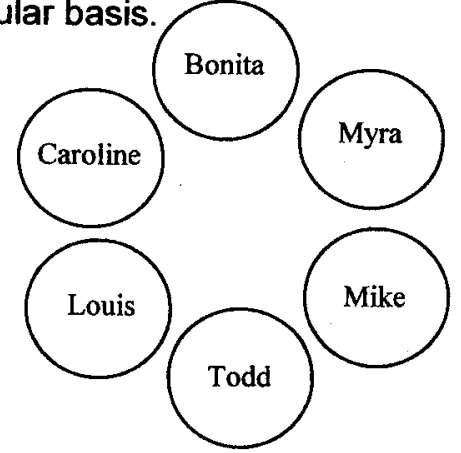

2. Individual quality of life-These circles represent the individual quality of life of each of the family members consistent with the Special Interest Group on Quality of Life (2000) conceptualization.

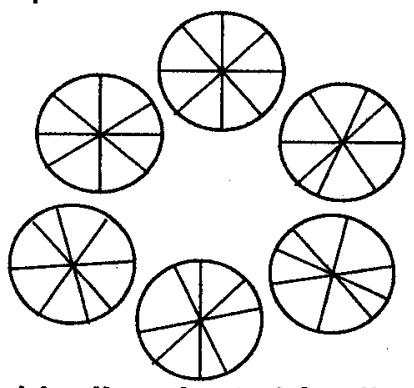

3. Individually-oriented family quality of life domains-We use overlapping circles here with six domains to illustrate the individually-oriented domains of family quality of life identified in this study that have an interactive impact.

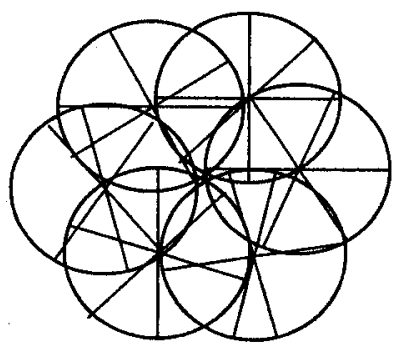

4. Family-oriented family quality of life domains-We use two ellipses to demonstrate the four family-oriented domains that provide a context within which individual family members live their life collectively as a unit.

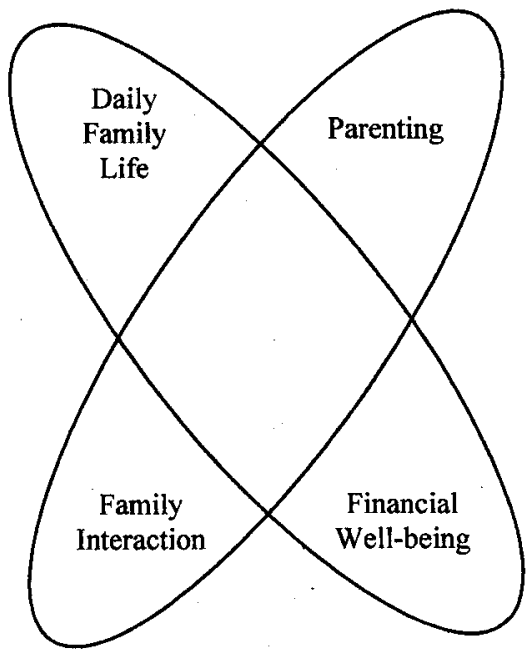

5. Combination of individually-oriented and family-oriented family quality of life domains-We combine the overlapping circles with the six individually-oriented domains for each family member. The two ellipses representing the four family-oriented domains serve as the context for the interaction of the individual members.

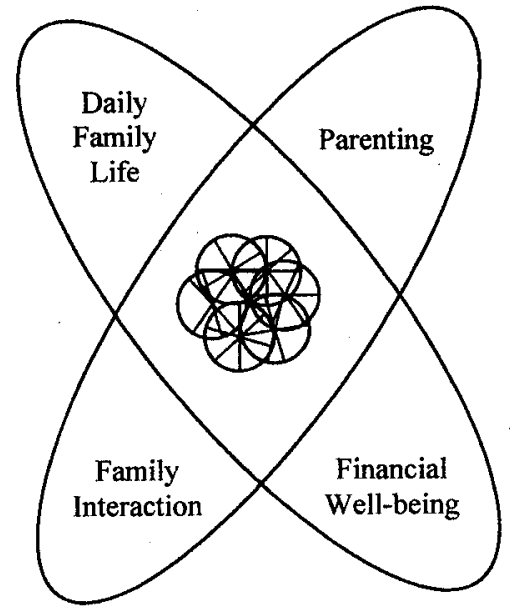

Figure 1 Key issues and visual depiction related to family quality of life. 


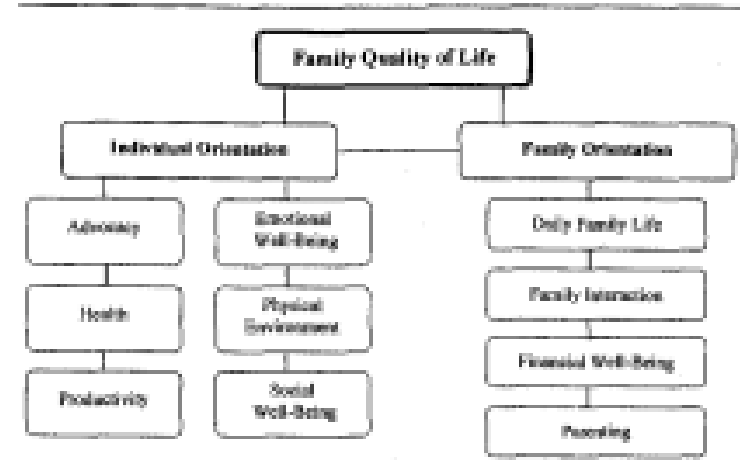

Figure 2 Ten domains of farnily quality of life.

Caroline was the one family member who spent a tremendous amount of time on advocacy. Neither Myra nor Bonita assumed any advocacy responsibilities, and the same applied to Mike, Todd, and Louis. Caroline and Bonita stayed at home for a large part of the day so their physical environment was the home, whereas each boy was currently enrolled in a different school and spent a large part of his day in his own unique physical setting. Myra was currently in a rehabilitation program; therefore, her physical environment was totally different from the other family members. Regarding health, Bonita's health challenges related to lupus presented idiosyncratic issues for her that were totally unrelated to those experienced by any of the rest of the families.

Our research team had extensive discussions on the similarities and differences between individual quality of life domains and individually oriented family quality of life domains. The key difference, again, is that individual quality of life focuses only on what is happening with the individual, whereas the individually oriented domains focus on how what is happening to the individual has an impact on other family members. One could examine Myra's individual quality of life and gain an understanding of the impact that her mental health and addiction challenges had on her individually, but it is a totally different analysis to also consider the impact of those challenges on her three children, her mother, and her sister.

Domains with a family orientation occur at the family unit level rather than at the individual family member level. Family-oriented domains provide a context within which individual family members live their life collectively as a unit as illustrated in Figure 1, Number 4. Typically, all family members tend to experience more similarity in the family oriented domains as contrasted to the individually oriented domains.
Within the Bell family, Caroline, Bonita, and the three boys generally shared the same schedule in their daily family life, the same type of family interaction, access to the same financial resources, and a similar style of parenting (four family domains). Myra, as the one individual who did not share the same household as the other five, had more differences from the others. The significant factors related to these differences were her mental health and addiction challenges. If it were not for these complicating factors, she would share much more in common with the other family members in terms of the family-oriented domains.

In a holistic sense, we illustrate our interpretation of the integration of family-oriented and individually oriented domains in Figure 1, Number 5. The illustration depicts the family-oriented domains serving as the context for the interaction and reverberation of the individual members.

\section{Family Quality of Life Domain Definitions, Subdomains, and Indicators}

Table 3 provides the domain definition, subdomains, and indicators for each subdomain for the six domains that have an individual orientation. Table 4 includes the domain definition, subdomains, and indicators for each subdomain for the four domains with a family orientation.

\section{Contrast in Perspectives of Parents of Children With and Without Disabilities}

Across all domains, our analysis indicates that the concerns of parents of children with disabilities were more intense and generally more frequent than the concerns expressed by parents of children without disabilities. We contrasted the perspectives of parents of children with and without disabilities in light of the individually oriented and the family oriented domains.

\section{Individually Oriented Domains}

Within the six individually oriented domains, the most substantial differences in perspectives of families of children with and without disabilities occurred in the domains of Advocacy, Emotional Well-Being, and Social Well-Being.

Advocacy. Advocacy is the domain where the greatest discrepancy existed between the comments of parents of children with and without disabilities. Families of children without disabilities spoke in very general terms about seeking to advance opportunities for their children, but their comments in no way mirrored the intensity and frequency of the comments of parents of children with disabilities, 
Table 3 Individually Oriented Domains, Subdomains, and Indicators

\begin{tabular}{|c|c|}
\hline Domain/Subdomain & Indicator \\
\hline \multicolumn{2}{|l|}{ Advocacy $^{\mathrm{a}}$} \\
\hline Advocacy role & Family members advocate when and where they want. \\
\hline Advocacy activities & $\begin{array}{l}\text { Family members advocate to improve services and outcomes for } \\
\text { themselves and/or other family members. }\end{array}$ \\
\hline Facilitators of advocacy & $\begin{array}{l}\text { Family members have support from others to advocate } \\
\text { successfully. }\end{array}$ \\
\hline \multicolumn{2}{|l|}{ Emotional Well-Being ${ }^{\mathrm{b}}$} \\
\hline Identity & $\begin{array}{l}\text { Family members feel a sense of pride in their own and each } \\
\text { others' accomplishments. }\end{array}$ \\
\hline Respect & $\begin{array}{l}\text { Family members are treated with respect by people outside the } \\
\text { family. }\end{array}$ \\
\hline Reducing stress & Family members are able to take time for themselves. \\
\hline Choice & Family members have opportunities to make choices. \\
\hline \multicolumn{2}{|l|}{ Health $^{\mathrm{c}}$} \\
\hline Physical health & Family members have the best possible physical health. \\
\hline Mental health & Family members have the best possible mental health. \\
\hline Health care & Family members can get medical care on a regular basis. \\
\hline \multicolumn{2}{|l|}{ Environmental Well-Being ${ }^{\mathrm{d}}$} \\
\hline Home environment & My family's home has enough space. \\
\hline School environment & My children are safe at school. \\
\hline Work environment & Family members are safe at work. \\
\hline Neighborhood and community environment & $\begin{array}{l}\text { My family lives in a community that has services to meet my } \\
\text { family's needs. }\end{array}$ \\
\hline \multicolumn{2}{|r|}{ (2) } \\
\hline Education & $\begin{array}{l}\text { My child with a disability is receiving an appropriate education } \\
\text { (diagnosis, IEP, inclusion, behavior support). }\end{array}$ \\
\hline Work & Family members balance work and family life. \\
\hline Leisure & Family members can participate in the hobbies they enjoy. \\
\hline Personal development & Family members support each other's growth and development. \\
\hline \multicolumn{2}{|l|}{ Social Well-Being ${ }^{\mathrm{f}}$} \\
\hline Social acceptance & Family members are accepted by people they meet. \\
\hline Social relationships & Family members have friends. \\
\hline Social support & $\begin{array}{l}\text { Family members get practical help from people outside the } \\
\text { family. }\end{array}$ \\
\hline
\end{tabular}

${ }^{a}$ Activities that family members undertake to learn and act on behalf of themselves and each other. ${ }^{\mathrm{b}}$ The feeling aspects of life. ${ }^{c}$ Physical and mental well-being. ${ }^{\mathrm{d}}$ The conditions of the physical contexts within which family members live. ${ }^{\mathrm{e}}$ Skills and opportunities to participate and succeed in education, work, and leisure. ${ }^{\mathrm{f}}$ Skills and opportunities to have relationships with people outside the family.

many of whom described their advocacy efforts (especially with the education and health systems) with anger, frustration, and fatigue. They often used metaphors related to battle to describe advocacy--fighting, ammunition, guns, combat. "It's a fight, it is a daily battle to get anything you need for exceptional children. You fight the teacher, you fight the principal, and you fight the superintendent. It's very frustrating to do all those battles."

Parents of children with disabilities who do not speak English expressed a strong need to learn how to deal with the many intricacies of obtaining services and supports for their children-especially qualifying for Medicaid, learning about options for 
Table 4 Family-Oriented Domains, Subdomains, and Indicators

\begin{tabular}{|c|c|}
\hline Domain/Subdomain & Indicator \\
\hline \multicolumn{2}{|l|}{ Daily Family Life ${ }^{a}$} \\
\hline Family care & My family provides care to family members. \\
\hline Daily activities & $\begin{array}{l}\text { My family members do chores within the home (cleaning, cooking, } \\
\text { yard work). }\end{array}$ \\
\hline Getting help & My family plans for help from others (finding, asking, supervising). \\
\hline \multicolumn{2}{|l|}{ Family Interaction ${ }^{\mathrm{b}}$} \\
\hline Positive interactional environment & My family members feel loved and accepted by each other. \\
\hline Communication & My family members talk openly with each other. \\
\hline Supporting each other' & My family members help each other. \\
\hline Flexibility & $\begin{array}{l}\text { My family can fairly quickly make plants to do things without a lot } \\
\text { of complicated planning. }\end{array}$ \\
\hline \multicolumn{2}{|l|}{ Financial Well-Being ${ }^{\mathrm{c}}$} \\
\hline Paying for basic necessities & My family can pay for basic necessities (housing, food, clothing). \\
\hline Paying for health care & My family can pay for health care. \\
\hline Paying for other needs & My family can pay for childcare. \\
\hline Sources of income & My family has salary and benefits from employment. \\
\hline Financial security & My family is financially secure. \\
\hline \multicolumn{2}{|l|}{ Parenting $^{\mathrm{d}}$} \\
\hline Providing parental guidance & My family helps our child(ren) learn right from wrong. \\
\hline Discipline & My family sets boundaries and rules for our child(ren). \\
\hline Teaching & My family helps our child(ren) with school work. \\
\hline
\end{tabular}

paying for health care, and learning about their child's educational rights.

Emotional well-being. Parents of children with disabilities spoke more strongly about the need to be listened to, understood, and respected by professionals as an aspect of their emotional well-being. They described more stress in terms of dealing with service systems than they described in terms of stress of dealing directly with their child's special needs. Many recounted in detail how teachers, health care professionals, and other human service professionals acted in a way that they described as disrespectful. Parents reported feeling very sad and frustrated that they and their family members were not respected, especially by people whose job it is to support them. One mother recalled:

It made me very upset. Some things that they were saying about my son, about how bad he is, he won't sit down, he don't listen, things like this. But why would they do this if they know this child has special needs? Why would you put all this junk in their folder? But they are ignoring his special needs. No one is trying to help him or show him attention.

In addition, parents of children with disabilities described stresses associated with child characteristics, particularly problem behavior. One mother said:

Sometimes I wish I had died because my son is like this... and this child is so hyper. He don't sit. He's on medication, ya know. He screams, he's loud. He says talk things. He cannot shut-up. He don't listen. And I don't have help at all.

Across all groups, respondents expressed their concerns that they did not have enough time to do all of the things that were important to them, resulting in feeling overcommitted and not having time to devote to their own personal needs.

Social well-being. Although families of children with and those without disabilities described issues related to social well-being, the degree to which social acceptance was an issue and the intensity of associated feelings was much greater for families of 
children with disabilities, many of whom reported grave concerns about their child's acceptance, with most comments describing negative experiences. Many reported that they had a very high priority with regard to their child with a disability developing friendships. They also described the impact that the family member's disability had on their own friendships, typically relating to the discomfort their friends experienced regarding their child with a disability.

\section{Family-Oriented Domains}

Within the four family-oriented domains, the major differences between the perspectives of families of children with and without disabilities occurred in the Family Interaction and Parenting domains.

Family Interaction. Many respondents spoke about family in an ideal sense as a place of love, acceptance, harmony, and nurturance. Participants described factors that enabled them to have a harmonious family life, including spending time together, clarifying roles for the adults, respecting each others' individuality, offering unconditional love and support, and having open and honest communication.

Families of children with disabilities talked about needing more support to enable them to do things together as a family or to participate in activities with their other children. A particularly problematic theme arose in many of the comments of parents of children who experienced problem behavior or complicated medical conditions. These parents lamented the fact that they frequently felt tethered to their child and simply could not make spontaneous plans to go to movies, out to dinner, or, in some cases, even out of the room:

When things are going well, we can do what we want. We can actually walk out of the room and do stuff. I can go down to the basement and do some work on something and leave him alone for a minute or two and not have to worry. You know, we can sit him outside and we can do some yard work and not have to be right by him, you know. In case something goes wrong.

Parenting. One of the major differences between parents of children with and without disabilities was the additional emphasis that parents of children with disabilities put on discipline and teaching. A major complicating factor related to discipline was the extent of the child's problem behavior, whereas it appeared that the major complicating factor related to teaching the children was a lack of individualization on the part of teachers, resulting in children with disabilities falling farther and farther behind in school.

Many parents of children with disabilities talked about the need to learn more about behavioral interventions they could implement with their children. Although some of them described timeout and/or token systems that they had used somewhat successfully, they expressed the need for more information.

Additional parenting responsibilities for parents of children with disabilities occurred in the subdomain of teaching. Parents of children with mild disabilities who had extensive homework discussed the time and effort it took for them to help their children in the evening. Typically, children with more severe disabilities did not have homework.

\section{Discussion}

This research extends the excellent work that has been done in the developmental disability field related to the conceptualization and measurement of individual quality of life (Cummins, 1997; Felce, 1997; Goode, 1997; Hughes \& Hwang, 1996; Schalock, 1996, 1997, 2000; Schalock et al., 2002). The only other conceptualization of family quality of life domains across the lifespan within the disability field comes from the previously mentioned threecountry study involving Australia, Canada, and Israel (Brown, Davey et al., in press; Brown, Isaacs et al., in press; Neikrug et al., in press). These researchers identified the following nine domains: Health, Financial Well-Being, Family Relationships, Support From Other People, Support From Disability-Related Services, Spiritual and Cultural Beliefs, Careers and Preparing for Careers, Leisure and Enjoyment of Life, and Community and Civic Involvement. Table 5 compares the domains generated in this study with the domains in the three-country study. In terms of individually oriented domains overall, our interpretation is that the individual domains and subdomains generated in the present study are broader than those in the three-country study. For example, our domain of Productivity includes four subdomains-Education, Work, Leisure, and Personal Development. This domain incorporates two of the domains from the three-country study -- (a) Careers and Preparing for Careers and (b) Leisure and Enjoyment of Life -- but it is broader than those two domains alone, also including Education and 
Table 5 Comparison of Domains Generated in This Study and Three-Country Study

\begin{tabular}{ll}
\hline This study & \multicolumn{1}{c}{ Three-country studies } \\
\hline Advocacy & $\mathrm{XX}^{\mathrm{a}}$ \\
Health & Health \\
Productivity & Careers and Preparing for Careers; Leisure and Enjoyment of Life \\
Emotional Well-Being & Spiritual and Cultural Beliefs \\
Social Well-Being & Support From Other People \\
Physical Environment & $\mathrm{XX}$ \\
$\mathrm{XX}$ & Community and Civic Involvement \\
$\mathrm{XX}$ & Support from Disability-Related Services \\
Daily Family Life & $\mathrm{XX}$ \\
Family Interaction & Family Relationships \\
Financial Well-Being & Financial Well-Being \\
Parenting & $\mathrm{XX}$ \\
\hline
\end{tabular}

Note. See text for references.

${ }^{\mathrm{a}}$ No comparable domain.

Personal Development. Another example is the Social Well-Being domain in this study, which includes the three subdomains of Social Acceptance, Social Relationships, and Social Support, and is broader than the three-country study domain of Support From Other People. Furthermore, in terms of family-oriented domains, the domains in this study overlap with two domains in the three-country studyFamily Interaction (called Family Relationships in the three-country study) and Financial Well-Being. The three-country study, however, did not have comparable domains to Daily Family Life and Parenting, which are family-oriented domains in this study. The three-country study identified Support From Disability-Related Services as a discrete domain, whereas we incorporated support from disability-related services into the particular domain to which the support was related (e.g., we coded support from physicians within the Health domain).

Our study pointed to the importance of Physical Environment (subdomains of Home, School, Work, and Neighborhood/Community Environment), but the three-country study did not have a comparable domain, whereas they identified Community and Civic Involvement, and our study had no comparable domain. Examination of the qualitative comments from the parents in our study showed that none of them mentioned community and civic involvement as an important component of their quality of life. Our sense is that the pressing issues and demands related to other family concerns relegated community and civic involvement to a negligible contributing element to respondents' family quality of life.

Our study was based on qualitative inquiry, enabling us to gain the firsthand perspectives of 137 family members who represented an extremely diverse background in terms of ethnicity, age, educational background, income, geographical location, age of child, and type/extent of disability. In addition, we heard from 50 professionals also representing diverse characteristics who worked in the fields of education, human/social services, and health care. The authors of the three-country study, on the other hand, based their domains on in-depth discussions of the research team and a review of family research.

\section{Implications for Research}

We plan to proceed into future phases of research with the long-term goal of developing a psychometrically sound scale for measuring family quality of life. To accomplish this goal, we will use the domains, subdomains, and indicators (see Tables 3 and 4) to undertake a national field test for the purpose of conducting exploratory and confirmatory factor analyses and item analyses in order to develop a family quality of life scale with a rigorous factor structure, a succinct number of items, and acceptable reliability and validity.

Once we have adequate psychometric properties, we anticipate using this scale to gain the perspectives of all family members regarding a rating of importance and satisfaction. The importance rating 
will enable families to individualize their responses in choosing the indicators that are meaningful to them personally out of the range of indicators that were suggested by the focus group participants. By including an importance dimension, we hope to minimize the chance that researchers and families will perceive the indicators as standards to which all families should subscribe. We anticipate exploring alternative methods for aggregating scores of individual family members in order to obtain the score at the family unit of analysis and for exploring the similarities and differences in response patterns of various family members. One of the weaknesses of family research in the disability field to date has been the tendency to use only mothers and, in far fewer cases, fathers as the unit of analysis when purporting to measure family perspectives. In recent statistical methodology Maguire (1999) has proposed methods for using the individual responses of different family members within hierarchical linear modeling. In addition, structural equation modeling can be used to determine the amount of agreement or disagreement among family members across different domains (Ferketich, Figuerdo, \& Knapp, 1991; Figuerdo, Ferketich, \& Knapp, 1991; Sidani \& Jones, 1995). These methods enable the individual perspectives of family members to be considered while simultaneously having the family as the overall unit of analysis.

\section{Implications for Family Support}

Although we believe it is critically important to have a family quality of life scale for family research, we are also eager to develop a family quality of life survey that we anticipate can be used in agencies both at the individual family level and at the program evaluation level. In terms of individual family usage, we intend to develop a family-friendly survey that can be used collaboratively with families in planning for delivery of family-centered services and supports. We envision that such a survey might be completed by families in a rating checklist format, or domains, subdomains, and indicators could be used as probes in interviews or conversations with families in gathering information open-endedly.

Our use of a participatory action research approach has enabled us to be in frequent contact with families and service providers about their preferences regarding how a family quality of life survey might be most useful. Families have frequently warned us that they do not want any kind of survey that would result in a score because of two grave concerns: (a) if they receive a low score, they do not want it to be perceived as having a "family quality of life quotient" that would deem them as "dysfunctional" and (b) if they score too high, they do not want loss of supports and services. Thus, our anticipation is to use a "map" that will chart important scores against satisfaction scores to enable families and service providers to identify items around which families perceive the most importance where there is the least amount of satisfaction (Council, 2000). As our work evolves, we hope to develop a bank of potential actions and resources for each item so that families and service providers can have ready linkages between family priorities and support options.

On the program evaluation level, we believe the process that Gardner and Nudler (1999) developed for using personal outcomes of individuals with disabilities as the basis for program evaluation and enhancement is highly relevant to the use of family quality of life outcomes as the basis for program enhancement. Agency administrators who are seeking to enhance their effectiveness in improving family outcomes can benefit from aggregated data, across all families being served, concerning their perceptions of importance and satisfaction of various indicators.

In summary, we believe that the field has had the rhetoric of family-centered services and the enhancement of family outcomes for at least a decade. The next logical step is to match that rhetoric with a conceptual framework that will guide the evolution of research and family support over time to ultimately produce significant and sustainable enhancements in families' outcomes.

\section{References}

Accreditation Council on Services for People With Disabilities (1995). Outcome measures for early childhood intervention services. Towson, MD: Author.

Allen, R. I., \& Petr, C. G. (1996). Toward developing standards and measurements for family-centered practice in family support programs. In G. H. S. Singer, L. E. Powers, \& A. L. Olson (Eds.), Redefining family support: Innovations in publicprivate partnerships (pp. 57-86). Baltimore: Brookes.

Bailey, D. B., \& McWilliam, P. J. (1993). The search for quality indicators. In P. J. McWilliam \& D. B. 
Bailey (Eds.), Working together with children and families (pp. 3-20). Baltimore: Brookes.

Bailey, D. B., McWilliam, R. A., Darkes, L. A., Hebbeler, K., Simeonsson, R. J., Spiker, D., \& Wagner, M. (1998). Family outcomes in early intervention: A framework for program evaluation and efficacy research. Exceptional Children, 64, 313-328.

Brotherson, M. J., \& Goldstein, B. L. (1992). Quality design of focus groups in early childhood special education research. Journal of Early Intervention, 16(4), 334-342.

Brown, I., Isaacs, B., McCormack, B., Baum, N., \& Renwick, R. (in press). Family quality of life in Canada. In A. P. Turnbull, I. Brown, \& H. R. Turnbull (Eds.), Family quality of life: An international perspective. Washington, DC: American Association on Mental Retardation.

Brown, R., Davey, R., Shearer, J., \& Kyrkou, M. (in press). Family quality of life in Australia. In A. P. Turnbull, I. Brown, \& H. R. Turnbull (Eds.), Family quality of life: An international perspective. Washington, DC: American Association on Mental Retardation.

Council on Quality and Leadership in Supports for People With Disabilities. (2000). Importance/ satisfaction map: A guide for exploring satisfaction with services. Towson, MD: Author.

Cummins, R. A. (1997). Assessing quality of life. In R. I. Brown (Ed.), Quality of life for people with disabilities: Model, research and practice (pp. 116-150). Cheltenham, UK: Thornes.

Dunst, C. J., Johnson, D., Trivette, C. M., \& Hamby, D. (1991). Family-oriented early intervention policies and practices: Family-centered or not? Exceptional Children, 58, 115-126.

Erlandson, D. A., Harris, E. L., Skipper, B. L., \& Allen, S. D. (1993). Doing naturalistic inquiry: A guide to methods. Newbury Park, CA: Sage.

Felce, D. (1997). Defining and applying the concept of quality of life. Journal of Intellectual Disability Research, 41, 126-135.

Ferketich, S. L., Figuerdo, A. J., \& Knapp, T. R. (1991). The Multitrait-Multimethod approach to construct validity. Research in Nursing and Health, 14, 315-320.

Figuerdo, A. J., Ferketich, S. L., \& Knapp, T. R. (1991). More on MTMM: The role of confirmatory factor analysis. Research in Nursing and Health, 14, 387-391.

Gardner, J. F., \& Nudler, S. (Eds.). (1999). Quality performance in human services: Leadership, values, and vision. Baltimore: Brookes.

Glaser, B., \& Strauss, A. L. (1967). The discovery of grounded theory: Strategies for qualitative research. Chicago: Aldine.

Goode, D. (1997). Quality of life as international disability policy: Implication for international research. In R. L. Schalock (Ed.), Quality of life. Vol. II: Application to persons with disabilities (pp. 211-221). Washington, DC: American Association on Mental Retardation.

Hughes, C., \& Hwang, B. (1996). Attempts to conceptualize and measure quality of life. In R. L. Schalock (Ed.), Quality of life. Vol. I: Conceptualization and measurement (pp. 51-61). Washington, DC: American Association on Mental Retardation.

Iceland, J. (2000). The "family/couple/household" unit of analysis in poverty measurement. Retrieved September $27, \quad 2001, \quad$ from http://www.census.gov/hhes/poverty/povmeas/ papers/famhh3.html\#2.

Krueger, R. A. (1994). Focus groups: A practical guide for applied research (2nd ed.). Newbury Park, CA: Sage.

Lincoln, Y. S. (1995). Emerging criteria for quality in qualitative and interpretive research. Qualitative Inquiry, 1, 275-289.

Lincoln, Y. S., \& Guba, E.G. (1985). Naturalistic inquiry. Beverly Hills, CA: Sage.

Maguire, M. C. (1999). Treating the dyad as the unit of analysis: A primer on three analytic approaches. Journal of Marriage and the Family, 61, 213-223.

Maxwell, J. A. (1996). Qualitative research design: An interactive approach (Vol. 41). Thousand Oaks, CA: Sage.

Neikrug, S. M., Judes, J., Roth, D., \& Krauss, B. (in press). Family quality of life in the Israeli family with a developmentally disabled child. In A. P. Turnbull, I. Brown, \& H. R. Turnbull (Eds.), Family quality of life: An international perspective. Washington, DC: American Association on Mental Retardation.

Patton, M. Q. (1990). Qualitative evaluation and research methods. Newbury Park, CA: Sage.

Rubin, H. J., \& Rubin, I. S. (1995). Qualitative interviewing: The art of hearing data. Thousand Oaks, CA: Sage.

Santelli, B., Singer, G. H. S., DiVenere, N., Ginsberg, C., \& Powers, L. (1998). Participatory action research: Reflections on critical incidents in a 
participatory action research project. Journal of the Association for Persons with Severe Handicaps, 23, 211-222.

Schalock, R. L. (1996). Quality of life and quality assurance. In R. Renwick, I. Brown, \& M. Nagler (Eds.), Quality of life in health promotion and rehabilitation: Conceptual approaches, issues, and applications (pp. 104-118). Thousand Oaks, CA: Sage.

Schalock, R. L. (1997). Can the concept of quality of life make a difference? In R. L. Schalock (Ed.), Quality of life Vol. II: Application to persons with disabilities (pp. 245-267). Washington, DC: American Association on Mental Retardation.

Schalock, R. L. (2000). Three decades of quality of life: Mental retardation in the 21 st century. In M. L. Wehmeyer \& J. R. Patton (Eds.), Mental retardation in the year 2000 (pp. 335-356). Austin, TX: Pro-Ed.

Schalock, R. L., Brown, I., Brown, R., Cummins, R. A., Felce, D., Matikka, L., Keith, K. D., \& Parmenter, T (2002). Conceptualization, measurement, and application of quality of life for persons with intellectual disabilities: Report of an international panel of experts. Mental Retardation, 40, 457-470.

Sidani, S., \& Jones, E. (1995). Use of the Multitrait Multimethod (MTMM) to analyze family relational data. Western Journal of Nursing Research, 17, 556-570.
Turnbull, A. P., Friesen, B. J., \& Ramirez, C. (1998). Participatory action research as a model for conducting family research. Journal of the Association for Persons with Severe Handicaps, 23, 178-188.

Turnbull, A. P., Turbiville, V., \& Turnbull, H. R. (2000). Evolution of family-professional partnership models: Collective empowerment as the model for the early 21 st century. In J. P. Shonkoff \& S. L. Meisels (Eds.), The handbook of early childhood intervention (2nd ed., pp. 630650). New York: Cambridge University Press.

Received 10/23/01, first decision 2/1/02, accepted 7/11/02

Editor-in-charge: Steven J. Taylor

\section{Authors:}

Denise J. Poston, PhD, Research Associate (E-mail: denisep@ku.edu); Ann P. Turnbull, PhD, CoDirector; Hasheem Mannan, MS, Research Assistant; and Mian Wang, PhD, Beach Center on Disability; Janet Marquis, PhD, Co-Director, Research Design and Analysis Unit, Life Span Institute, The University of Kansas, Haworth Hall, 1200 Sunnyside Ave., Rm. 3136, Lawrence, KS 66045. Jiyeon Park, PhD, Professor, Special Education, Ewha University, Seoul, South Korea.

This research was supported by a grant from the National Institute on Disability and Rehabilitation Research to the Beach Center on Disability, Grant \#H133B980050. 